\title{
PRIMEIRO EMPREGO: COMO TREINAR O ENFERMEIRO RECÉM-GRADUADO
}

\author{
Renata Aparecida Belei * \\ Sandra Ribeiro * \\ Maria do Carmo Lourenço Haddad ** \\ Marli T. Oliveira Vannuchi ***
}

\begin{abstract}
RESUMO - Os autores da pesquisa baseados em informaçõesde enfermeiros recémgraduados e dados da literatura, propõem uma sistemática de treinamento para o recém-formado em seu primeiro emprego, que pode ser utilizada pela instituição empregadora, com a finalidade de diminuir as ansiedades dos profissionais de enfermagem no início de suas carreiras.
\end{abstract}

ABSTRACT - The authors of the search set in informations of recently graduates nurses and literature bases, propose a training systematics to the recently graduate on his first employment that can be used for the employer institutions, with the intention of decreasing the nursing professionals worries on the start of their profession.

\section{INTRODUÇÃO}

O primeiro emprego do enfermeiro sempre é visto como um desafio acompanhado de inúmeras dificuldades que geram ansiedades e até mesmo frustrações.

A primeira dificuldade relatada pelos recém-formados, refere-se ao precesso admissional onde as empresas não explicitam com clareza suas expectativas em relação ao desempenho do profissional; não esclarecem a filisofia da instituição e poucas vezes apresentam seus regimentos internos.

O recém-formado coloca também a necessidade de um treinamento prévio, direcionado ao setor de atuação. Este treinamento seria uma forma de adaptação ao seu local de trabalho, pois como recém-graduados sentem-se despreparados emocionalmente e tecnicamente para assumirem as responsabilidades de gerenciar uma unidade de atendimento e ainda coordenar os trabalhos de uma equipe de enfermagem, que na maioria das vezes possui experiência profissional muito maior que a deles. Ressaltam que este treinamento deve ser acompanhado de uma supervisão direta e indireta de um enfemeiro responsável pela Educação em Serviço e após o prazo estipulado para treinamento, toma-se indispensável um feed-back como forma de retorno do enfermeiro sobre seu de- sempenho, diminuindo assim suas ansiedades.

Estes profissionias queixam-se tembém do descaso com que são tratados nas instituições empregadoras, que muitas vezes não levam em consideração suas dificuldades profissionais, inexperiências administrativas e os colocam em unidades especializadas sem trcinamneto prévio, exigindo o máximo do desempenho técnico, causando no recém-graduado mais ansiedade e atraso no processo de adaptação.

Observa-se também que esta experiência é única para o recém-graduado, sendo comentada somente no início da carreira e que após alguns meses de vivência da prática profissional, ou mudança do primeiro emprego, ultrpassam essas dificuldades e não fazem mais comentários tão ansiosos.

Considerando os aspectos acima mencionados, os autores desta pesquisa realizaram uma revisão bibliográfica sobre o assunto e propõem uma sistemática de treinamento do recém-formado, que possa ser utilizada pelas instituições empregadoras, com a finalidade de diminuir as ansiedades desses profissionais no início de suas carreiras.

\footnotetext{
* Enfermeira da Santa Casa de Londrina - Pr.

** Professor-assistente do Departamento de Enfermagem da Universidade Estadual de Londrina - Pr.

*** Prof essor-Adjunto do Departamento de Enfermagem da Universidade Estadual de Londrina - Pr.
} 


\section{REVISÃO BIBLIOGRÁFICA}

IDE $^{8}$ relata o testemunho de vários enfermeiros sobre o impacto que sofrem no início da carreira profissional, na qual encontram dificuldades no exercício das atividades específicas de enfermagem, incongruências entre seus anseios e as propostas feitas pelo mercado de trabalho.

Segundo ALHADEFF ${ }^{1}$, o recém-graduado em enfermagem encontra muitas difículdades no início do exercício prossional, somente adquirindo habilidade após várias execuções das técnicas e no momento em que domina o medo decorrente da falta de conhecimento. Ressalta ainda, que é a escola a culpada em não apontar o caminho a ser seguido após o curso.

KRAMER apud FRINKELSTEIN ${ }^{7}$ analisa a crise de identidade de recém-graduado, resultante das divergências entre os sistemas de valores da instituição e aqules aprendidos na escola. No campo de atuação da cnfermagem existe uma grande distância entre 0 saber teórico e a prática. São cobradas muito mais tarefas administrativas do que aquelas que envolvem competências técnicas.

PINHEIROS ${ }^{11}$ já relatava, em 1952 uma discrepância entre o ensino e o serviço, decorrente da ação da escola e a realidade dos serviços, que exigem dos recém-formados o desempenho de tarefas de liderança nas áreas administrativas e de ensino de enfermagem.

Existem conflitos entre enfermeiros e instituições de saúde devido ao desajuste entre o processo de informação e utilização do profissional.

OLIVEIRA $^{10}$, comenta que os cursos de graduação de enfermagem tendem a desenvolver um programa de aprendizagem, para estimular os estudantes a internalização dos valores da enf ermagem como profissão autônoma, cujo centro das atenções é o indivíduo que necessita de ajuda para reter ou alcançar a saúde. Porém, logo no início de sua vida profissional os enfermeiros descobrem que são outras as espectativas das instituições de saúde, ou melhor, tais espectativas são muito vagas e não há espaço para novos autônomos. Este mesmo autor acrecenta que os recém-formados são enquadrados em tarefas administrativas, raramente coordenando assistência de enfermagem. Ressalta que os enfermeiros acabam por preencher os vazios administrativos da organização, que podem incluir a coordenação da assistência de enf ermagem, e que certamente inclui a sobrecarga de taref as gerenciais que os afastam do paciente, dificultando o seu desempenho técnico. Sem autonomia para influenciar na organização e, ao descobrir que os serviços de enfermagem não têm, na organização, a posição compatível com o volume e a responsabilidade do trabalho desenvolvido, o jovem profissional, frustrado em suas aspirações de modelos, com sua eficiência, procura outro caminho para melhor realizar-se, ou acomoda-se às exigências institucionais.

RONCÁGLIA $^{12}$ realizou um trabalho sobre as dificuldades encontradas pelo recém-graduado ao assumir suas funções frente ao "status" de enfermeiro. $O$ fato do recém-graduado possuir conhecimento para exercer a profissão, não implica que tenha condições para assumir as responsabilidades que advêm do seu novo status. A pesquisa inclui recém-graduados no primeiro emprego e enfermeiros trabalhando ha mais de três meses no cargo. Conclui que há uma discrepância do que o recém-graduado espera encontrar frente ao que é esperado dele. Não há coincidência quanto ao que se orienta ao recém-graduado e ao que se espera dele. Em muitos casos houve orientação somente nos aspectos administrativos, sem ênfase para a assistência de enfermagem.

CHAVES 5 comenta que o indivíduo bem utilizado, é aquele que tem a oportunidade de aplicar ao limite os conhecimentos e habilidades que adquiriu; $e$ o indivíduo sub-treinado procura fugir de situações em que possa defrontar-se com tarefas que são esperadas dele e para as quais ele não foi preparado; o indivíduo super-treinado sente-se igualmente diminuido, frustrado, quando confinado a tarefas que poderiam ser feitas por pessoas de um nível educacional e ocupacional inferior. DI $\mathrm{LASCIO}^{6}$ refere que o estudante habilitado, para receber o título de enfermeiro não é um produto acabado. A conclusão do curso de graduação habilita-o para exercício inicial de sua carreira profissional, à semelhança do que ocorre com outras profissões. Esta compreensão deve ser ressaltada ao estudante no decorrer do curso, primeiro porque o conhecimento científico está constantemente sujeito a revisão, e segundo porque a experiência é condição indispensável para se atingir níveis cada vez mais elevados de maturidade profissional.

Outro aspecto importante que pode agravar este processo é descrito por $\mathrm{BUENO}^{3}$, que afirma que os enfermeiros questionam sobre a profissão, evidenciando um momento de crise na enfermagem ligados a problemas de ordem individual, profissional, institucional e social. Referem também várias dificuldades relacionadas à inserção da profissão no setor saúde e contexto social, tais como:

- Desvalorização da profissão.

R. Bras. Enferm., Brasilia, 45 (4) : 308-312, out./dez. 199230 
- Falta de reconhecimento do papel do próprio enfermeiro.

- Baixa remuneração salarial.

- Falta de oportunidades para treinamento e reciclagem.

- Falta de experiência prática (insegurança profissional).

- Dificuldades em aplicar corretamente os conhecimentos adquiridos na escola.

- Dificuldade no relacionamento com a equipe de saúde.

\section{OBJETIVO}

Elaborar uma sistemática de treinamento para o recém-graduado que possa ser utilizado pelas instituições empregadoras.

\section{METODOLOGIA}

A elaboração do instrumento que propõe uma sistemática de treinamento para recém-graduado, foi baseada em relatos informais de enf ermeiros com até seis meses de conclusão do curso, os quais destacaram as dificuldades apresentadas no primeiro emprego. Utilizou-se também informações obtidas através da revisão bibliográfica.

\section{SISTEMÁTICA DE TREINAMENTO DO ENFERMEIRO RECÉM-GRADUADO}

Acreditando que um bom processo de integração do recém-graduado no seu primeiro emprego se inicia no treinamento, descreveremos os aspectos que julgamos mais importantes e que devem ser considerados para facilitar essa integração e permitir que o recémformado vença suas primeiras barreiras e se torne um enfermeiro competente.

A formação de uma equipe de enfermagem eficiente inicia-se durante o processo de recrutamento, seleção, e treinamento de pessoal. ${ }^{9}$

No processo de recrutamento é muito importante que a instituição explicite o perfil do profissional que deseja selecionar, destacando os pontos mais importantes que são exigidos, tais como:

- grau de formação e especialização;

- necessidaade de experiências anteriores;

- se é importante o estado civil;

- limite de idade e outros.
É necessário também explicitar, para que setor é a vaga, a remuneração e o horário do trabalho.

Destaforma, o processo será racionalizado, eevitará que profissionais menos preparados submetam-se a seleção, além de evitar um desgaste emocional para os candidatos que não preencham os pré-requisitos.

Para o processo de seleção se faz necessário que os serviços tenham bem definidos os critérios de avaliação, que deverão ser elaborados por uma comissão designada para este fim ou pelo setor de educação em serviço, quando houver.

Ressaltamos que processos de seleção extensos e muitos criteriosos, nem sempre selecionam os melhores candidatos. O importante é identificar os enfermeiros que apresentem as melhores condições de desenvolverem suas habilidades teórico-práticas.

Nesta fase de seleção, se o candidato apresentar um bom potencial, já poderá receber algumas informações sobre a instituição, com a finalidade de motivá-lo ao novo emprego, iniciando-se assim o processo de treinamento.

A integração de qualquer funcionário em uma instituição é muito importante e tem a finalidade de introduzí-lo e familiarizá-lo com os objetivos, filosofia e dinâmica do serviço.

Para o recém-formado essa integração se faz muito necessária, considerando ser a sua primeira experiência profissional, onde o domínio da prática é pequeno. Para muitos desses profissionais esta é a sua primeira grande experiência de vida, e assumir tantas responsabilidades os assusta e provoca ansiedades.

Por mais que o recém-graduado tenha tido um bom desempenho na escola, e até mesmo algumas experiências profissionais como aluno bolsista, apresenta-se ansioso e preocupado com a nova experiência, o que é natural e descrito por muitos autores. ${ }^{6,8,10,11}$

Os chefes dos serviços de enfermagem quando admitem recém-formados, devem considerar os aspectos acima mencionados e elaborar um programa de treinamento que contemple o desenvolvimento de habilidades práticas e que atenda também aos aspectos emocionais do novo profissional.

Para isso é necessário que o recém-graduado passe por um processo de treinamento formal de pelo menos um mês, sob a responsabilidade do setor de educação em serviço ou de um enfermeiro designado para este fim.

O treinamento deverá ser realizado da seguinte forma: no primeiro dia, durante as duas primeiras 
horas do período, receberá informações sobre seus direitos e deveres com a instituição. Estes itens poderão ser apresentados por um funcionário de recursos humanos. As próximas horas deverão ser utilizadas para visitar todas as dependências da instituição que deverão ser mostradas sem ressaltar os pormenores da dinâmica de funcionamento de cada uma. $O$ final do período ficará reservado para apresentação do pessoal e unidade onde ficará lotado. Fazer essa apresentação de maneira informal e de preferência ressaltando as qualidades e "manias" de cada elemento da equipe, e se possível do próprio recém-graduado.

No segundo dia, no mesmo horário receberá informações sobre a instituição quanto aos aspectos relacionados à história, filosofia, responsabilidade da instituição com a comunidade, equipe de trabalho, especialidades que atendem, sistema de organização da empresa, regulamentos, usos e costumes da instituição. A seguir o enfermeiro deverá ser encaminhado para a unidade onde ficará lotado, para se inteirar da retina e normas do setor. Se a unidade possuir normas e rotinas escritas o recém-graduado poderá analisá-las sozinho, e no final do período esclarecer as dúvidas com o responsável por seu treinamento. Se não possuir, o responsável pelo treinamento, explicará para o novo enfermeiro toda a organização da unidade.

Desta forma; acreditamos que o recém-graduado já se inicia no reconhecimento da unidade e equipe, facilitando o processo de adaptação ao novo emprego.

No terceiro dia, no primeiro horário, receberá orientação sobre os procedimentos técnicos que são utilizados no setor onde trabalhará. Neste momento poderá identificar quais as técnicas que terá que dominar e fará uma auto-avaliação do seu desempenho teórico e prático nesta área, para identificar os pontos teóricos que deverá rever para facilitar o seu desempenho como líder da equipe. Nas últimas duas horas do dia, ficará na umidade acompanhando o supervisor de enf ermagem em suas atividades.

Julgamos que dessa maneira o recém-graduado poderá identificar sem muita ansiedade, pois ainda não está atuando, as sua dificuldades teórico-práticas, que deverão ser sanadas em estudos complementares fora do horário de trabalho, ou através de treinamento prático e formal na própria instituição.

Para a empresa, identificar as dificuldades do recém-admitido se toma necessário, pois isto direcionará o treinamento prático e também determinará o tempo que o enfermeiro deverá permanecer em treinamento até que possa assumir a liderança da unidade.
Para o quarto dia, o primeiro horário será reservado para discutir o programa do treinamento prático a ser realizado. Neste dia o enfermeiro poderá tirar sua dúvidas em relação aos aspectos organizacionais da instituição. $O$ restante do período deverá ser utilizado para que o recém-graduado continue acompanhando o enfermeiro na unidade em suas tarefas para ir se familiarizando com elas.

A participação do recém-graduado na elaboração do seu programa de treinamento é muito importante, pois como ele identificou previamente as suas necessidades teórico-práticas, poderá elaborar uma programação que atenda às suas necessidades e se sentirá mais responsável pelo processo de treinamento.

Neste treinamento prático, devem ser desenvolvidos principalmente os aspectos técnicos dos procedimentos de enfermagem, para que o recém-graduado desenvolva habilidades psecomotoras.

Observamos que um dos aspectos que aumentam a ansiedade do recém-graduado é a falta de habilidade psicomotora, o que é confirmado também por outros autores. ${ }^{1,3,6,8}$ Acreditamos que quando no treinamento esse aspecto é bem desenvolvido, parte das dificuldades do profissional já são sanados.

Outro ítem importante que deve ser abordado no treinamento, são os aspectos de liderança em enfermagem. Sabemos que o recém-graduado recebeu em sua formação informações de como liderar uma equipe, mas nesta fase irá colocar esses conhecimentos em prática, onde as dúvidas poderão surgir. Recomendamos que esse tópico deve ser abordado no último dia de treinamento, quando os enfermeiros já vivenciaram um período com a sua equipe de trabalho.

Do quinto ao décimo dia, o primeiro horário do período deverá sempre ser utilizado para oo treinamento e o restante para o recém-graduado acompanhar o enfermeiro da unidade.

No décimo primeiro e no décimo segundo dia, quando o treinamento já deve ter sido concluído, 0 recém-graduado deverá iniciar o seu turno na unidade de lotação sempre acompanhado pelo enfermeiro do setor. E a partir do décimo terceiro dia poderá ficar sozinho sem a supervisão do enfermeiro, que o assessorará à distância se for solicitado. Este esquema deverá permanecer até o final do primeiro mês.

$O$ recém-graduado deverá durante esse período realizar encontros semanais com o responsável pelo seu treinamento para discutir as dificuldades, avaliar seu desenvolvimento e programar novos estudos se necessário.

R. Bras. Enferm., Brasilia, 45 (4) : 308-312, out./dez. 1992311 
Acreditamos que ao final do primeiro mês o enfermeiro se encontre apto a assumir integralmente a supervisão da unidade sob suas responsabilidades.

Esta proposta de treinamento foi elaborada baseada nas vivências dos autores, não sendo possível testá-la neste momento, o que será feito em data oportuna.

Lembramos que o treinamento deverá ser testado e adaptado à realidade de cada serviço, consederando as especificidades dos mesmos.

Para as unidades de terapia intensiva, centro cinúrgico, hemodiálise e outros, o treinamento deverá ser mais especializado e ter maior duração.

Ressaltamos que não basta treinar os recém-graduados, é preciso acompanhar a aplicação prática dos conhecimentos que lhes foram transmitidos, testar a sua validade e verificar se os enfermeiros adotaram atitudes diferentes e mais eficientes no desempenho de suas funções. Se os resultados não forem os esperados, investigue se a causa está nos métodos de treinamento ou na sua má aplicação. ${ }^{9}$

\section{CONCLUSÃO}

Um treinamento bem conduzido, possibilitará uma boa integração do recém-graduado no seu primeiro emprego, com menor desgaste emocional para o enfermeiro, pois o mesmo percebe o interesse da empresa por ele, despertando atitudes favoráveis e um sentimento de integração em sua equipe.

A instituição também será beneficiada com este processo, pois o funcionário quando percebe que não foi bem recebido e que não houve qualquer esforço no sentido de facilitar seu entrosamento com o grupo de trabalho, ele os abandona e procura novo ambiente.

\section{REFERÊNCIAS BIBLIOGRÁFICAS}

1. ALHADEFF, G. Anxiety in a new graduate. Am.J.Nurs, New York, v.79, p.688, apr.1979.

2. BENDO, M.A., CELIDÔNIO, M.A., PERFEITO,I.S.N.C. et al. Proposta metodológica para orientação de funcionário recém-admitido em hospital. Revista Brasileira de Enfermagem, Brasilia, v.41, n.1, p.69-74, jan./mar., 1988.

3. BUENO, S.M.V., VIETTA, E.P., FREITAS, D.M.V. Inserção do enf ermeiro na profissão: uma abordagem relacional de sua formação com a vivência profissional. Revista Brasileira de Enfermagem, Brasilia, v.40, n.2/3, p.157-66, abr./set., 1987.

4. CASTELLANOS, B.E.P. Algumas reflexões sobre nossa profissão: a enfermagem. Revista Paulista de Enfermagem, São Paulo, v.2, p.42-4, nov./dez., 1982.

5. CHAVES, M. DE M. Saúde e sistemas. Rio de Janeiro, Fundação Getúlio Vargas, 1972.

6. DI LASCIO, C.M.D.S. Preparo, no curso de graduação, para a integração do enf ermeiro recém-graduado na vida profissional. Revista Brasileira de Enfermagem, Rio de Janeiro, v.23, n.3/6, p.57-75, jul./dez., 1970.

7. FINKELSTEIN, R. Reflections of a former new graduate. Imprint, New York, v.26, n.5, p.50-1, dec. 1979.
8. IDE, C.A.C., PADILHA, K.G., PIERIN, A.M.G. et al. O seguimento do graduado em enf ermagem. Revista Brasileira de Enfermagem da USP, São Paulo, v.19, n.3, p. 195 221, dez.1985.

9. MEZOMO, J.C. Administração de recursos humanos no hospital. São Paulo. Centro São Camilo de Desenvolvimento em Administração da Saúde, 1984, p.126-145.

10. OLIVEIRA, M.I.R. O enf ermeiro e a enfermagem. In: Congresso Brasileiro de Enfermagem, 33, 1981, Manaus. Anais... Associação Brasileira de Enf ermagem, 1981,p.1921.

11. PINHEIRO,M.R.S. A inclusão de Pedagogia, Supervisão e Administração no Curriculo das Escolas de Enfermagem. Anais de Enfermagem, v.5, n.4, p.327-328, 1952.

12. ROCÁGLIA, E., MARESCA, P., MIGITA, M.A.P. Considerações gerais sobre inicio de carreira. Revista Brasileira de Enfermagem, Rio de Janeiro, v.28, n.4, p.59-69, out./dez. 1975.

13. VARGENS, O.M.C. Em busca de um espaço. Enfermagem. $O$ Jornal Brasileiro de Enfermagem, Rio de Janeiro, v.11, n.79, p.3, maio/jum. 1987. 